\title{
Adaptation of the Early Childhood Behavior Problem Screening Scale (ECBPSS) to Turkish
}

\author{
Songül GIREN, H. Gözde ERTÜRK-KARA, Muhammed ÖZTÜRK \\ Aksaray University, Aksaray, Turkey
}

\begin{abstract}
This study aims to adapt the Early Childhood Behavior Problem Screening Scale (ECBPSS) to Turkish. This scale is developed to identify the behavioral problems of preschool children. The study used a cohort of 254 children (50\% boys and 50\% girls) selected randomly among 3-6 years old children attending to the independent kindergartens and nursery classes administered by Aksaray province national education directorate. We managed to obtained the teacher questionnaire for 235 children $(51.1 \%$ boys and $48.9 \%$ girls) and the parent questionnaire for 254 children ( $50 \%$ boys and $50 \%$ girls). The scale is translated to Turkish and the psychometricsuit ability of the translation is evaluated. Its construct validity is tested with exploratory and confirmatory factor analysis. Factor analyses showed that both the teacher and parent questionnaires of the Turkish version of ECBPSS consist a single dimension and nine items. For the reliability calculation of the scale, we used the Cronbach's alphainternal consistency coefficients and interrater correlation levels. Cronbach reliability coefficients of the teacher and parent questionnaires are 0.89 and 0.88 , respectively. Interrater correlation value is found as 0.99 . In conclusion, we managed to prepare a scale for the use of researchers, teachers, and field experts.
\end{abstract}

Keywords: early childhood education, problem behaviors, assessment, adaptation, Early Childhood Behavior Problem Screening Scale (ECBPSS)

\section{Introduction}

Preschool education starts with the birth and continues till the child starts to attend primary school. Children are expected to complete their social, emotional, mental, language, psychomotor, and self-care developments, and to be able establish and maintain healthy communications with other individuals. Adaptation to the social life and socialization processes are examples in terms of social-emotional development (Alisinanoğlu \& Kesicioğlu, 2010, p. 93; Taner Derman \& Başal, 2013, p. 112). According to Sertbaş (2006), children encounter with new information and skills in every stage of development. This entails many problems to be solved (Akman, Baydemir, \& Akyol, 2011, p. 1716). Adaptation problems experienced during this period leads to problematic behaviors. Problematic behaviors in children can be internal or external. External problematic behaviors are the extreme behaviors that express the insufficient socialization. Children showing external problematic behaviors lack of self-care and this leads to uncontrolled behaviors. These types of behaviors expressanger, aggression, and disappointment directed against other individuals (Aunola \& Nurmi,

Songül GİREN, asistant professor, Departmentof Early Childhood Education, Aksaray University.

H. Gözde ERTÜRK-KARA, asistant professor, Departmentof Early Childhood Education, Aksaray University.

Muhammed ÖZTÜRK, lecturer, Ph. D. student, Departmentof Early Childhood Education, Aksaray University. 
2005, p. 1144). Breaking the rules, hyperactivity, unable to self-restraint, and aggression against peers are most common external problematic behaviors seen in preschool children (Campbell, Shaw, \& Gilliom, 2000, p. 3, as cited in Campell, 1990). Internal problematic behaviors are expressed as somatic symptoms, depression, anxiety, fear, unease, heaviness, and alienation/introversion. In these behaviors, negative emotions are directed to self instead of others. It is believed these behaviors develop due to over developed self regulation skill (Özbey \& Alisinanoğlu, 2009, p. 494; Aunola \& Nurmi, 2005, p. 1144).

\section{Literature Review}

Problematic behaviors in children increase starting from age two (Gardner \& Shaw, 2008, p. 882). Communicative disorders, mildmental disorders, and behavioral problems are most common behavioral disorders during childhood. But, we know very few about whether these behaviors have a genetic or environmental origin (Plomin \& Dale, 2000, as cited in Trouton, Spinath, \& Plomin, 2002, p. 444). As most of the time, other disorders accompany these disorders and they appear in infancy or early childhood, we cannot speak of its genetic or environmental dependency with certainty (Trouton, Spinath, \& Plomin, 2002, p. 444). But, it is believed that behavioral problems during preschool period is effected both by biological and environmental factors as they show great variations based on the nursing service provided to the child, the environment, and the individual characteristics of the child (such as temperament, sociality, and attention span). Biological and prenatal environmental factors are especially effective during this period (Gardner \& Shaw, 2008, p. 883).

In social sciences, the main objective of the researchers, decision makers, and service providers is to develop valid and reliable tools to evaluate human behaviors (Epstein, Ryser, \& Pearson, 2002, p. 208). There are many tools to evaluate children with emotional and behavioral problems. Although the assumptions, items, measures, and data collection processes of these tools differs, their common point is to identify the deficiencies, problems, and pathologies of the children and to provide a basis to decision makers by providing them the necessary information (Lappalainen, Savolainen, Kuorelahti, \& Epstein, 2009, p. 746; Epstein, Ryser, \& Pearson, 2002, p. 208). Nelson, Epstein, Griffith, and Hopper (2007) claimed that evaluation tools and screening scales aimed at children should meet some basic criteria. According to Walker, Ramsey, and Gresham (2004), screening scales should be short and easily applicable (Walker et al., 2004, as cited in Nelson et al., 2007, p. 149). Moreover, screening scales should be compatible with the level of children, and provide valid and reliable psychometric features (Nelson et al., 2007, p. 149). Systems aiming to evaluate the behavioral problems of preschool children should meet the criteria of being compatible with the age of children and using the observations of parents and teachers (Gardner \& Shaw, 2008, p. 882).

Studies show that problematic behaviors started in early childhood tend to continue in the late childhood and even in the puberty, and to be the heralds of other problems, such as social and academic failures or drug addiction (Schubert Center for Child Studies, 2009). This is why, early pedagogical evaluations is critical in determining the problems and developing appropriate intervention programs. This process also causes great changes in teachers, special education experts and other field experts (Alisinanoğlu \& Kesicioğlu, 2010, pp. 93-95; Lappalainen et al., 2009, p. 751). This study aims to adapt the Early Childhood Behavior Problem Screening Scale (ECBPSS) to 3-6 age group Turkish children. This scale is specially developed to identify preschool or nursery class children in risk of developing problematic behaviors at home or school. For this, we searched answer to these research questions: 
1. Is the parent questionnaire of ECBPSS, valid in determining the behavioral problems of Turkish children?

2. Is the parent questionnaire of ECBPSS, reliable in determining the behavioral problems of Turkish children?

3. Is the teacher questionnaire of ECBPSS, valid in determining the behavioral problems of Turkish children?

4. Is the teacher questionnaire of ECBPSS, reliable in determining the behavioral problems of Turkish children?

\section{Method}

\section{Study Sample}

Study sample consisted of 254 children (50\% boys and 50\% girls) selected randomly among 3-6 years old children attending to the independent kindergartens and nursery classes administered by Aksaray province national education directorate. We managed to obtainthe teacher questionnaire for 235 children (115 girls and 120 boys) and the parent questionnaire for 254 children (127 girls and 127 boys).

\section{Data Collection Tools}

ECBPSS is a specially developed tool to identify preschool or nursery class children in risk of developing problematic behaviors at home or school. Scale consists of two sub-dimensions and two questionnaires for collecting the evaluations of teachers and parents regarding the children (Nelson et al., 2007).

ECBPSS-parent questionnaire. ECBPSS is originally a scale with 12 items and used to evaluate the behaviors of 3-6 year group children. It uses 4-point Likert scale with following items: "This looks a lot like my child" (3), "This looks like my child" (2), "This does not look like my child" (1), and "This does not look like my child at all" (0). Items of the scale are prepared according to the reading-understanding level of a 6th grader. ECBPSS helps us to determine two sub-dimensions: "total behavioral problem point" and "internal-external problematic behaviors." High points point to higher levels of perceived problems (Epstein \& Nelson, 2006).

ECBPSS-teacher questionnaire. This is the same questionnaire with the parent questionnaire. This is also originally a scale with 12 items and used to evaluate the behaviors of 3-6 year group children. It uses 4-point Likert scale with following items: "This looks a lot like the child" (3), "This looks like the child" (2), "This does not look like the child" (1), and "This does not look like the child at all" (0). Items of the scale are prepared according to the reading-understanding level of a 6th grader. ECBPSS helps us to determine two sub-dimensions: "total behavioral problem point" and "internal-external problematic behaviors." High points point to higher levels of perceived problems (Epstein \& Nelson, 2006).

\section{Data Collection}

ECBPSS asks from raters to rate behaviors they observed for three months or more. This is especially emphasized in our study. All items from both questionnaires are filled for every child individually.

\section{Data Analysis}

Parent and teacher questionnaires were evaluated with Kaiser-Meyer-Olkin (KMO) and Barlett tests. Factor structure was analyzed with an exploratory factor analysis run on Statistic Package for Social Science (SPSS) 18 package program and a confirmatory factor analysis run on Linear Structural Relations (LISREL) 
8.7 package program. The reliability of the scale was calculated using Cronbach's Alpha $(\alpha)$ and interrater correlation methods.

\section{Findings}

\section{On the Validity of the Scale}

Validity of language: Translation of the scale was done by three preschool education experts proficient in English. This translation was translated back to English by two preschool education expert proficient in English and a foreign language (English) education field expert. Then, scale items were evaluated by five experts (two preschool education experts, one foreign language education expert, and two assessment and evaluation experts). After these, it was decided that English and Turkish version are loyal to each other.

\section{On the Validity of Scope of the Parent Questionnaire}

Besides, both questionnaires were evaluated by three preschool education experts in terms of their validity. Experts had agreed upon the validity of the scope of the scale.

\section{On the Structural Validity of the Parent Questionnaire}

Obtained data was subjected to exploratory factor analysis. One of the most common techniques to determine the sufficiency of the sample size in exploratory factor analysis is the KMO technique. KMO value of the scale was determined as 0.89 . KMO values between 0.8 and 0.9 are considered as the sign of a very good sample size (Hutcheson \& Sofroniou, 1999, as cited in Seçer, 2013, p. 119). Barlett's Test of Sphericity also produced a significant value. Taking these values in consideration, we moved to the exploratory factor analysis and tried to determine whether it measures the required structure or not. Table 1 provides the Eigen values and percentage of explained variations about how many factors covered the variables (items).

Table 1

Eigen Values and Explained Variations of the Parent Questionnaire

\begin{tabular}{lll}
\hline Component number & Eigen value & Explained variation (\%) \\
\hline 1 & 5.181 & 43.175 \\
2 & 1.860 & 15.501 \\
\hline
\end{tabular}

We can see in Table 1 that there are two components with Eigen values over 1.00'in, thus, scale has a structure containing two factors. But the facts that the Eigen value of the first component is almost three times bigger than the Eigen value of the second component and there is not much difference between the Eigen value of the second component and the Eigen value of the rest, proves that the parent questionnaire has actually only one dimension (Lord, 1980, as cited in Duyan \& Gelbal, 2008, p. 44). The first component alone explains the $43.175 \%$ of the variation, two together explains $58.676 \%$. Scree plot of the Eigen values of components is given in Figure 1.

When the line chart is examined, we can see that items can be covered under one factor. Factor loads of the parent questionnaire are given in Table 2.

Accepted level of acceptance for item factor load was determined as 0.32 (Çokluk, Şekercioğlu, \& Büyüköztürk, 2012). When we look at the factor loads of the items, we can see that the factor loads of the first factors are quite high and vary between 0.399 and 0.838 . Nonetheless, the items number 9,11 , and 12 has more loads in the second factor. In case of a more than 0.10 point difference between the factor loads in two 
dimensions, it is more appropriate to transfer the factor load to the bigger one (Büyüköztürk, 2007). So, we decided to exclude these items from the scale. After the exploratory factor analysis, the revised version is accepted as valid, because the parent questionnaire is capable of measuring the intended structure as shown by the high percentage of the explained variation and high factor loads of the 9 remaining items in the first factor. When the results of the confirmatory factor analysis performed on the parent questionnaire is examined; we saw these goodness-of-fit (GFI) indices: root mean square error of approximation (RMSEA): 0.15, Chi-square/s $d=181.51 / 27$, normed fit index (NFI): 0.93, non-normed fit index (NNFI): 0.92, comparative fit index (CFI): 0.94, incremental fit index (IFI): 0.94, relative fit index (RFI): 0.91, root mean square residual (RMR): 0.05, GFI: 0.86, and adjusted goodness-of-fit index (AGFI): 0.77 . When the results of the modification indices are examined; we saw high modification indices for item 6 and 7, and deem them worthy of investigation. The researchers evaluated the contribution to the GFI indices when the correlation between these items left free, and decided to apply the necessary modification. The results of the second confirmatory factor analysis, performed after the modificationare given in Figure 2 and Table 3.



Figure 1. Scree plot of the Eigen values of components (parent questionnaire).

When the results of the factor analysis diagram in Figure 2 are examined, we see that the factor loads of the items vary between 0.39 and 0.78 , and they were significant $(p<0.01)$. The results of the GFI tests (Chi-square, GFI, RMSEA, CFI, NFI, NNFI RFI, IFI, and AGFI) are given in Table 3.

When the Chi-square and degree of freedom values in Table 3 are divided (67.07/25), we get 2.68. As this ratio is below 3, we can say that it is a perfect fit. When RMSEA value is examined, we see that the value 0.08 is an acceptable GFI. The acceptable level for NFI, NNFI, RFI, IFI, AGFI, and GFI indices is 0.90 , and perfect fit for the same indices is 0.95 . When evaluated on this basis, we saw that CFI, NFI, NNFI, RFI, and IFI values are perfect and GFI and AGFI values are acceptable. RMR with a 0.05 value points to a good fit (Şimşek, 2007, 
as cited in Seçer, 2013, p. 152). In conclusion, we can say that the established model has a very good fit with the data, and thus, the scale has structural validity. So, we can accept that the parent questionnaire can measure the behavioral problems in children.

Table 2

Factor Loads of the Parent Questionnaire

\begin{tabular}{llc}
\hline Items & Factor I & Factor II \\
\hline s1 & 0.533 & 0.186 \\
s2 & 0.784 & -0.105 \\
s3 & 0.736 & 0.139 \\
s4 & 0.809 & -0.041 \\
s5 & 0.648 & -0.341 \\
s6 & 0.838 & -0.228 \\
s7 & 0.811 & -0.267 \\
s8 & 0.708 & -0.143 \\
s9 & 0.385 & 0.570 \\
s10 & 0.549 & -0.349 \\
s11 & 0.399 & 0.781 \\
s12 & 0.442 & 0.690 \\
\hline
\end{tabular}



Chi-Square $=67.07, d f=25, p-v a l u e=0.00001$, porses $=0.082$

Figure 2. Diagram of the second confirmatory analysis applied to the parent questionnaire.

Table 3

GFI Indices of the Parent Questionnaire

\begin{tabular}{lllllllllll}
\hline Chi-square & $S D$ & CFI & GFI & NFI & RMSEA & NNFI & RFI & IFI & AGFI & RMR \\
\hline 67.07 & 25 & 0.98 & 0.94 & 0.97 & 0.08 & 0.97 & 0.96 & 0.98 & 0.90 & 0.05 \\
\hline
\end{tabular}

\section{On the Structural Validity of the Teacher Questionnaire}

The same procedure was run for this questionnaire. We saw that the sample size is acceptable for the exploratory factor analysis $(\mathrm{KMO}=0.88)$ and the result of Barlett's Test of Sphericityis significant (Hutcheson 
\& Sofroniou, 1999, as cited in Seçer, 2013, p. 119). Obtained data was first subjected to exploratory factor analysis. Table 4 provides the Eigen values and percentage of explained variations about how many factors covered the variables (items).

Table 4

Eigen Values and Explained Variations of the Teacher Questionnaire

\begin{tabular}{lll}
\hline Component number & Eigen value & Explained variation (\%) \\
\hline 1 & 5.347 & 44.557 \\
2 & 2.415 & 20.126 \\
\hline
\end{tabular}

The Eigen value of the first component is 5.347 , it is 2.415 for the second. Eigen value of the first component is almost three times bigger than the Eigen value of the second component. This result proves that the parent questionnaire can be investigated in one dimension. The first component alone explains the $44.557 \%$ of the variation, two together explains $64.683 \%$. Scree plot of the Eigen values of components is given in Figure 3.



Figure 3. Scree plot of the Eigen values of the components (teacher questionnaire).

Factor loads of the items are given in Table 5.

When the factor loads of the items are examined, we saw higher load in the second factor in items 9,11 , and 12 like the parent questionnaire. Nonetheless, factors loads of the other items were higher in the first dimension (range 0.44 to 0.86 ). Thus, we decided to exclude these items from the questionnaire (Büyüköztürk, 2007) and to apply confirmatory factor analysis on the remaining items under one dimension. After the exploratory factor analysis, the revised version is accepted as valid, because the teacher questionnaire is capable of measuring the intended structure as shown by the high percentage of the explained variation and high factor loads of the 9 remaining items in the first factor. The GFI indices calculated after the confirmatory factor analysis is as follows: RMSEA: 0.13, Chi-square/s $d=141.99 / 27$, NFI: 0.94, NNFI: 0.93, CFI: 0.95, IFI: 0.95, RFI: 0.92, RMR: 0.04, GFI: 0.88, and AGFI: 0.80. When the results of the GFI indices are examined, we 
decided to evaluate structure by taking the results of the modification indices in consideration. Items 6 and 7 had high values, thus, they were deemed to be worthy of investigation. The researchers evaluated the contribution to the GFI indices when the correlation between these items left free, and decided to apply the necessary modification. The results of the second confirmatory factor analysis, performed after the modification are given in Figure 4 and Table 6.

Table5

Factor Loads of the Teacher Questionnaire

\begin{tabular}{llc}
\hline Items & Factor I & Factor II \\
\hline s1 & 0.449 & 0.417 \\
s2 & 0.818 & -0.265 \\
s3 & 0.528 & 0.475 \\
s4 & 0.865 & -0.188 \\
s5 & 0.700 & -0.262 \\
s6 & 0.838 & -0.110 \\
s7 & 0.864 & -0.124 \\
s8 & 0.784 & -0.118 \\
s9 & 0.250 & 0.820 \\
s10 & 0.827 & -0.185 \\
s11 & 0.202 & 0.874 \\
s12 & 0.326 & 0.573 \\
\hline
\end{tabular}



Figure 4. Diagram of the second confirmatory analysis applied to the teacher questionnaire.

When the results of the factor analysis diagram in Figure 4 are examined, we see that the factor loads of the items vary between 0.36 and 0.81 , and they were significant $(p<0.01)$. The results of the GFI tests (Chi-square, GFI, RMSEA, CFI, NFI, NNFI, RFI, IFI, and AGFI) are given in Table 6. 
Table 6

GFI Indices of the Teacher Questionnaire

\begin{tabular}{lllllllllll}
\hline Chi-square & $S D$ & CFI & GFI & NFI & RMSEA & NNFI & RFI & IFI & AGFI & RMR \\
\hline 69.00 & 25 & 0.98 & 0.94 & 0.97 & 0.08 & 0.97 & 0.96 & 0.98 & 0.89 & 0.04 \\
\hline
\end{tabular}

As seen in the Table 6, Chi-square value is 69.00 and the degree of freedom is 25 . When these values are divided (69.00/25), we get 2.76. As this ratio is below 3, we can say that it is a perfect fit. When RMSEA value is examined, we see that the value 0.08 is an acceptable GFI index. The acceptable level for NFI, NNFI, RFI, IFI, AGFI, and GFI indices is 0.90 , and perfect fit for the same indices is 0.95 . When evaluated on this basis, we saw that CFI, NFI, NNFI, RFI, and IFI values are perfect and GFI and AGFI values are acceptable. RMR with a 0.04 value points to a good fit (Şimşek, 2007, as cited in Seçer, 2013, p. 152). In conclusion, we can say that the established model has a very good fit with the data, and thus, the scale has structural validity. So, we can accept that the teacher questionnaire can measure the behavioral problems in children.

\section{On the Reliability of the Parent and Teacher Questionnaires}

In order to determine the reliability of the scale, we used Cronbach's Alpha $(\alpha)$ method. The reliability coefficient $(\alpha)$ of the parent questionnaire (12 items) is calculated as 0.86 . When total correlation of the items is examined, we saw a variation between 0.360 and 0.718 . Factor analyses showed that items 9,11 , and 12 overlap. Thus, these items are excluded from the scale. The reliability coefficient of the remaining 9 items was 0.88 . Total correlation of the items varies between 0.423 and 0.788 .

The reliability coefficient $(\alpha)$ of the teacher questionnaire (12 items) is calculated as 0.86 . When total correlation of the items is examined, we saw a variation between 0.309 and 0.737 . Factor analyses showed that items 9,11 , and 12 overlap. Thus, these items are excluded from the scale. The reliability coefficient of the remaining 9 items was 0.89 . Total correlation of the items varies between 0.366 and 0.814 .

Researchers also analyzed the interrater reliability of both questionnaires. The correlations of the parent and teacher questionnaires are given in Table 7.

Table 7

Reliability of the Parent and Teacher Questionnaires

\begin{tabular}{|c|c|c|c|c|c|}
\hline & \multicolumn{2}{|c|}{ Parent questionnaire } & \multicolumn{2}{|c|}{ Teacher questionnaire } & \\
\hline & $\mathrm{M}$ & $S D$ & $\mathrm{M}$ & $S D$ & \\
\hline Total problematic behavior & 17.21 & 5.76 & 17.07 & 6.08 & 0.99 \\
\hline
\end{tabular}

Note. $n=235 ;{ }^{*} p<0.01$.

When Table 7 is examined, the compatibility of ratings of two types on raters (parents and teachers) who observe the children's behaviors at home and school were very high (Hughes \& Garrett, 1990, as cited in Güler \& Taşdelen Teker, 2015, p. 14).

\section{Discussion, Conclusion, and Recommendations}

ECBPSS is a universal scale developed to identify the children under the risk of presenting problematic behaviors. We believe that by adapting the scale to Turkish, we opened a way to contribute to the literature by providing a tool for researchers, teachers, and field experts.

The language and scope validity of the Turkish questionnaires are approved by experts. Following factor analyses showed that these questionnaires are psychometrically valid and reliable to screen the behaviors of 
children during early childhood. Exploratory factor analysis proved that the scale actually has on dimension contrary to the original one. We also found high variation between the sub-dimensions of the parent and teacher questionnaires (Eigen values of the sub-dimensions of the teacher questionnaire: 5.347 and 2.415, Eigen values of the sub-dimensions of the parent questionnaire: 5.181 and 1.860). When the AFA results of the original scale are examined, we can see that both questionnaires consist of two dimensions (internal and external) (Eigen values of the sub-dimensions of the teacher questionnaire: 7.223 and 6.568, Eigen values of the sub-dimensions of the parent questionnaire: 5.673 and 2.252). Also, in the original version, both questionnaires consist of 12 items. But, we excluded three items in the both questionnaires in the Turkish version as a result of their low factor load. Confirmatory factor analysis showed a high modification value for items 6 and 7 in both questionnaires. We believe that this is due to close meaning of the two items. Item 6 states, "He/she is generally bad tempered and irritable," whereas item 7 states, "He/she is a ill tempered children." Raters might have thought that these items mean the same thing. GFI indices (Chi-square/sd, RMSEA, GFI, CFI, NFI, NNFI, IFI, RFI, RMR, and AGFI) after the modification were acceptable. Therefore, we saw that the both questionnaires are capable of determining the problematic behaviors of children. Reliability coefficients of the both questionnaires were high (parent questionnaire $\alpha=0.88$ and teacher questionnaire $\alpha=0.89$ ). Correlation between two questionnaires shows that these identify the problematic behaviors almost the same way. We believe that children present the same problematic behaviors both at home and school, thus, both raters (teacher and parent) rated objectively. Galejs and Stockdale (1982, p. 245) evaluated the social adequacy of children through the observations of their family, teachers, and peers. They found that evaluations of the family and teachers are more correlated than the observations of peers. Kumpulainenat et al. (1999, p. 46) evaluated the emotional and behavioral problems of children through the reports of their teachers and parents. They found that boys present more emotional/behavioral problems and parents and teachers provide compatible reports on the type of the problem. The original scale has a 0.36 interrater reliability. These authors believe that may be due to the different social roles of the parents and teachers. Raters may have differing perspectives as they observe the children in different context (Nelson et al., 2007, p. 153).

Expert opinions, our analysis and obtained results prove that the parent and teacher questionnaires of ECBPSS provide a valid and reliable scale to evaluate the problematic behaviors of children. ECBPSS has a very few items and can be applied in a very short time. This tool can provide a critical chance for preschool teachers, parents, caregivers, psychologists, child development specialists, etc. to identify the problematic behaviors of children at a very early age and to intervene. New researches can be performed using this scale with the aim of identifying the effect of various characteristics of the teachers, parents, and children (professional experience, stress/depression, child rearing approach, self sufficiency level, age, gender, etc.) on the problematic behaviors of the children.

\section{References}

Akman, B., Baydemir G., \& Akyol, T. (2011). The opinions of preschool teachers about problem behaviours which faced in classroom. e-Journal of New World Sciences Academy, 6(2), 1306-1311. (in Turkish)

Alisinanoğlu, F., \& Kesicioğlu, O. S. (2010). Examination of preschool children' sproblem behaviors in terms of different variables (Giresun sample). The Journal of Theoretical Educational Science, 3(1), 93-110. (in Turkish)

Aunola, K., \& Nurmi, J. E. (2005). The role of parenting styles in children's problem behavior. Child Development, 76(6), 1144 $-1159$.

Büyüköztürk, Ş. (2007). Data analysis handbook for social sciences. Ankara: Pegem Publishing. (in Turkish) 
Campbell, S. B. (1990). Behavior problems in preschool children: Clinical and developmental issues. New York: Guilford Press.

Çokluk, Ö., Şekercioğlu, G., \& Büyüköztürk, Ş. (2012). Multivariate statisti for social sciences, SPSS and LISREL implementations. Ankara: Pegem Publishing. (in Turkish)

Duyan, V., \& Gelbal, S. (2008). The adaptation study of Barnett liking of children scale to Turkish. Education and Science, 33(148), 40-48. (in Turkish)

Epstein, M. H., \& Nelson, J. R. (2006). Early childhood behavior problem screening scale. Lincoln: Center for At-Risk Children's Services, University of Nebraska.

Epstein, M., Ryser, G., \& Pearson, N. (2002). Standardization of the behavioral and emotional rating scale: Factor structure, reliability, and criterion validity. Brief Report, Journal of Behavioral Health Services \& Research, 29(2), 208-216.

Galejs, I., \& Stockdale, D. (1982). Social competence, school behaviors, and cooperative-competitive preferences: Assessments by parents, teachers, and school-age children. The Journal of Genetic Psychology: Research and Theory on Human Development, 2(141), 243-252.

Gardner, F. \& Shaw, D. S. (2008). Behavioral problems of infancy and preschool children (0-5). In M. Rutter, D. V. M. Bishop, D. S. Pine, S. Scott, J. Stevenson, E. Taylor \& A. Thapar (Eds.), Rutter's child and adolescent psychiatry (5th ed.). Oxford, U.K.: Blackwell Publishing Ltd.,.

Güler, N., \& Taşdelen Teker, G. (2015). The evaluation of rater reliability of openended items obtained from different approaches. Journal of Measurementand Evaluation in Educationand Psychology, 6(1), 12-24. (in Turkish)

Hughes, M. A., \& Garrett, D. E. (1990). Intercoder reliability estimation approaches in marketing: A generaliz ability theory frame work for quantitative data. Journal of Marketing Research, 27, 185-195.

Hutcheson, G. D., \& Sofroniou, N. (1999). The multivariate social scientist: An introduction to generalized linear models. Sage Publications.

Kumpulainen, K., Räsänen, E., Henttonen, I., Moilanen, I., Piha, J., Puura, K., Tamminen, T., \& Almqvist, F. (1999). Children's behavioural/emotional problems: A comparison of parents' and teachers' reports for elementary school-aged children. European Child \& Adolescent Psychiatry, 4(8), 42-47.

Lappalainen, K., Savolainen, H., Kuorelahti, M., \& Epstein, M. H. (2009). An international assessment of the emotional and behavioral strengths of youth. Journal of Child and Family Studies, 18(7), 746-753.

Lord, F. M. (1980). Applications of item response theory to practical testing problems. Hillsdale, N.J.: Lawrence Erlbaum Associates Publishers.

Nelson, R., Epstein, M., Griffith, A., \& Hopper, J. (2007). Factor structure, internal consistency, and interrater reliability of the early childhood behavior problem screening scale. Topics in Early Childhood Special Education, 27(3), 148-154.

Özbey, S. \& Alisinanoğlu, F. (2009). A study on problem behavior of 60-72 months children who attending public early childhood education institution. International Social Studies Journal, 2(6), 493-516. (in Turkish)

Schubert Center for Child Studies. (2009). Effects on emotional and behavioral problems from early childhood through adolescence. Retrieved from http://schubert.case.edu/files/2013/12/ connell_brief_final.pdf adresinden ulaş1lmıştır

Seçer, İ. (2013). Practical data analysis by using SPSS and LISREL. Ankara: Anı Publishing, 119, 152. (in Turkish)

Sertbaş, N. (2006). Behavioral problems in children at primary education and effectiv evariables (Unpublished master thesis, Dokuz Eylül University Educational Sciences Institute, İzmir, Turkey).

Şimşek, Ö. F. (2007). Introduction of structural equation modeling: Basic principals and LISREL implementations. Ankara: Ekinoks Publishing. (in Turkish)

Taner Derman, M., \& Başal, H. A. (2013). Relation between behavioral problems observed in preschool children and parental attitudes of families. Amasya Education Journal, 2(1), 115-144. (in Turkish)

Trouton, A., Spinath, F. M., \& Plomin, R. (2002). Twins early development study (teds): A multivariate, longitudinal genetic investigation of language, cognition and behavior problems in childhood. Twin Research, 5(5), 444-448.

Walker, H. M., Ramsey, E., \& Gresham, F. M. (2004). Antisocial behavior in school: Evidence-based practices (2nd ed.). Belmont, C.A.: Wadsworth/Thomson Learning. 